\title{
An Overview of International Literature on School Interventions to Promote Mental Health and Well-being in Children and Adolescents
}

\author{
Mauro Giovanni Carta ${ }^{1,2, *}$, Teresa Di Fiandra ${ }^{3}$, Lorenzo Rampazzo ${ }^{4}$, Paolo Contu ${ }^{1}$ and \\ Antonio Preti ${ }^{1,2}$
}

${ }^{1}$ Centro di Psichiatria di Consultazione e Psicosomatica, University Hospital, Cagliari, Italy; ${ }^{2}$ Department of Public Health and Clinical and Molecular Medicine, University of Cagliari, Cagliari, Italy; ${ }^{3}$ Italian Ministry of Health; ${ }^{4}$ Regione Veneto, Italy

This work was supported by Italian Collaborating Unit of the VII work package of the European Joint Action on Mental Health.

\begin{abstract}
Introduction: Mental disorders are the largest cause of the burden of disease in the world. Most of the burden affecting adult life has its onset during childhood and adolescence. The European Pact for Mental Health and Wellbeing calls for immediate action and investments in the mental health of children and adolescents. Schools may be the ideal location for promoting health and delivering healthcare services, since schools are a location where young people usually spend their daytime and socialize, schools are easily accessible to families, can provide non-stigmatizing health actions, and form links with the community. Aims and Goals of this Special Issue: This issue is developed within the framework of the Joint Action on Mental Health promoted by the European Commission. This special issue presents a set of systematic reviews on the evidence of the international literature on school interventions for the promotion of the mental health and wellbeing of children and adolescents. It is focused on five topical main areas: promoting general health and wellbeing; programs targeting specific mental disorders and conditions and integration of adolescents with mental health problems; Bullying; Sport; Alcohol and Drugs. An additional paper on the results of the largest epidemiological study conducted in some European countries on the prevalence and relative risk factors of mental disorders in school-age completes the issue. Conclusion: These reviews are a first contribution to address future European research and interventions, in particular about the multiple ways through which European policies could support the schooling and wellbeing of children and adolescents.
\end{abstract}

Keywords: Adolescent, children, Europe, intervention, mental health, school, well-being.

\section{INTRODUCTION}

Evidence is accumulating on the broad impact that the wellbeing experienced during childhood and adolescence may have across the life course of an individual in terms of physical and mental health. Indeed, most of the burden affecting the adult life of individuals has its onset during childhood and adolescence; in fact over $50 \%$ of mental disorders have their onset before adulthood [1, 2]. Mental disorders, including depression, bipolar disorder, anxiety disorders, psychoses within the spectrum of schizophrenia, intellectual disabilities and developmental disorders with their onset during childhood and adolescence, are widespread in the general population. According to current estimates, up to $30 \%$ of the European population suffer from a mental disorder during their lifetime [3, 4]. Even larger are the estimates of the subthreshold mental disorders, which do not reach the criteria for a full diagnosis but nevertheless impact on the quality of life and the wellbeing of those affected by them.

Mental disorders are increasingly recognized as the determinant of poor quality of life and health. Current estimates recognize mental disorders as the largest and growing cause of the burden of disease [5]. The burden attributable to

*Address correspondence to this author at the Centro di Psichiatria di Consultazione e Psicosomatica, University Hospital, Cagliari, Italy:

Tel: +39/070/6093495; E-mail: mgcarta@tiscali.ir mental health disorders and self-inflicted injuries is currently estimated as being higher than the burden of cardiovascular diseases and cancer [6].

Mental disorders negatively affect the entire life course of individuals, being the cause of substantial psychological, cognitive, social and occupational impairments and disabilities. Active and undertreated mental disorders are the cause of poorer educational outcomes, involve higher rates of selfinjuries and suicide, cause an increased involvement in unhealthy risk behaviors such as smoking, alcohol or drug abuse, poor diet, physical inactivity, which in turn result in an increased risk of physical illness and premature death [7]. The economic impact of mental disorders is huge for the individuals, their families and the society, because of increased health care utilization, lost productivity, unemployment, and of the costs attributable to increased antisocial behavior and crime [7].

Interventions aimed at improving the mental health and wellbeing of children and adolescents may have a broad impact on their developmental trajectories, resulting in a substantial reduction of the impairment and disability attributable to physical illness and mental disorders in adulthood, a decrease in suicide rates, and a diminution of mental health care utilization [7]. Additional benefits deriving from improved mental health of children and adolescents include improved educational outcomes, healthier lifestyle, e.g. a 
reduced involvement in unhealthy risk behaviors such as smoking and alcohol or drug use, a decrease of anti-social behavior and crime, and improved productivity at work as well as better social relationships.

Since many adult mental disorders have their onset during childhood or adolescence, early intervention and prevention of mental health disorders during childhood and adolescence are mandatory.

The European Pact for Mental Health and Wellbeing [8] calls for immediate action and investments to promote the mental health of children and adolescents. The 2013-2016 European Commission Joint Action on mental health and wellbeing [9] (http://www.mentalhealthandwellbeing.eu/) includes a work package on Mental Health and Schools, since schools have been identified as a major setting for interventions in favor of the mental health and well-being of children and adolescents in Europe [10].

School in general, and educational attainment in particular, are recognized amongst the fundamental determinants of the mental health of children and adolescents [11].

Schools may be the ideal location for promoting health and delivering healthcare interventions, since schools are a location where young people usually spend most of their daytime and socialize, schools are easily accessible to families, schools can provide non-stigmatizing health actions, and schools can provide appropriate and timely links with the community. As stated by the World Health Organization, "there is ample evidence that school based programs in elementary, middle and high schools can influence positive mental health and reduce risk factors and emotional and behavioral problems through socio-emotional learning and ecological interventions” [12].

Interventions targeting the school setting may be strategic in reaching those in need of treatment. Indeed, there is evidence that most of those who may benefit from potentially effective treatments do not approach treatment facilities because of barriers and impediments, including poor mental health literacy and preoccupations with stigma. This gives rise to a broad set of impacts and related economic costs [13].

The European Commission Joint Action on the mental health and wellbeing has recommended increased documentation of existing research, effective interventions and key research and key research to fill the gaps concerning the mental health and the wellbeing of children and adolescents, with particular attention to the school setting (Work Package 7) [10].

\section{AIMS AND GOALS OF THE REPORT}

This set of systematic reviews is intended to contribute to the goals established by the Work Package 7 on School of the 2013-2016 European Commission Joint Action; it is specifically aimed at offering a first comprehensive exploration of the existing literature with focus on five main areas that are topical to the wellness of children and adolescents:

1) The establishment of programs aimed at promoting general health and wellbeing in the school setting [14];
2) The provision of school-based programs targeting specific mental disorders and conditions, with attention to the integration of adolescents with specific mental health problems [15];

3) Bullying [16];

4) Sport [17];

5) Alcohol and Drugs [18].

We have added an additional paper on the results of the largest epidemiological study conducted in six European centers on the prevalence of mental disorders in school-age children and the relative risk factors [19]. This research work was supported by the same "Consumers, Health and Food Executive Agency” that promoted the Joint Action on Mental Health and well-being, and which this review forms part of. The synthesis of epidemiological research will provide those readers interested in exploring the themes covered in the review papers, with a framework that will provides information about the scale and the burden of the specific problems in different European contexts.

The main focus of this report is on the interventions aimed at prevention and/or treatment, so epidemiological studies have been omitted in the reviews. Furthermore, since the objective is to highlight interventions with proven effectiveness, particular attention has been given to studies with randomized controlled trial (RCT) design. Only in some cases studies with quasi-experimental design as cohort studies have been reported: this solution was opted for when specific areas lacked randomized controlled trials, or with reference to studies of particular interest that should stimulate randomized controlled trials.

Among the selected papers, only few studies were carried out in the European Union, a large amount were carried in the USA and some studies were found from Australia, Canada, New Zealand, Korea, India, China, Thailand, Chile, Norway and Switzerland. Overall, the results of these studies may suggest their extension or adaptation to the European Union, or at least could be interesting in the light of European policies. We have chosen to limit ourselves to the studies conducted in the European Union only in the area of research aimed at improving well-being through interventions on sport. European studies in this field are in fact numerous.

The first review details existing RCTs aimed at enhancing the youth's emotional and social skills to promote wellbeing and positive development [14]. There is ample evidence that personal skills (e.g., decision making, problem solving, creative thinking, critical thinking, effective communication, interpersonal relationship skills, self-awareness, empathy, coping with emotions, coping with stress) and positive factors in the social settings may contribute to positive growth and development [20,21], and positively impact on wellbeing reducing problems and risk-need concerns [23, 24]. The review focuses on programs that used a SAFE strategy, i.e. that are based on a step-by-step training approach (Sequenced), active forms of learning (Active), dedicate sufficient time to skill development (Focused), and have explicit learning goals (Explicit) [20-28]. These four recommended practices form the acronym SAFE [22]. 
Overall, 22 RCTs were identified on the basis of inclusion/exclusion criteria. Promising findings resulted about the effectiveness of universal school-based interventions that shift from a problem-focused approach to embrace a more positive view of mental health to promote the youth's wellbeing by improving their social and emotional skills.

The second review focuses on programs aimed at integrating children with psychiatric problems in the classroom [15]. The starting point of the review was the complex issues raised by school-based screening or treatment programs for common mental disorders. Indeed, several authors foreseen the danger of over-diagnosing students, increasing the risk of stigmatizing them with the life-long negative label of mentally disordered people, damaging their social interactions and peer acceptance. Evidence is accumulating that stigma and discrimination about mental health disorders are observed even in the youngest school children [29, 30].

To avoid the danger of stigmatization, there is some agreement that school-based programs should not merely assess clinical or cognition-based problems, but should also involve experiential activities, engaging students' feelings and behavior, and thus facilitating students' interaction with others. The review evaluates protocols' effectiveness by specifically taking into account social outcome or social skills as possible indicators of social inclusion/exclusion variables. The search strategy identified 27 RCTs according to the predefined inclusion criteria. Overall, 13 out of 16 studies that measured social dimensions showed that the interventions on these social variables had a positive impact, while 3 studies reported a non-statistically significant finding on social outcomes.

The third review focuses on Interventions against bullying at school [16]. Bullying can be defined as repeated aggressive behaviors perpetrated against a peer - the victim who cannot readily defend himself/herself because of physical size, social status or other factors that identify himself/herself as weaker than the aggressor [31]. The power differential between the victim and the aggressor is central to the definition of bullying. Most of the bullying behavior is aimed at undermining the social status of the victim and his/her sense of personal security, and at the same time the bully strives to increase his/her own personal value. As a consequence, the action of bullying usually takes place in front of an audience. Bystanders can support the bully, or contrast him/her; they are considered an integral part of the bullying behavior. Bullying is a very common problem of school environments and the effects of the exposition to bullying (as a victim, perpetrator, or bystander) are related to several mental health and social outcomes. On the one hand, the victims often experience various forms of psychological suffering related to anxiety and depression, or even selfdestructive behaviors [32], and the effects of that experience appear to last in time [33]. Bullies are, on the other hand, more frequently involved in delinquency and substance abuse than other children and adolescents [34].

The search strategy identified 17 RCTs according to the predefined inclusion criteria. Evidence was found to support the short-term effectiveness of the programs aimed at reducing bullying; however, their long-term effectiveness was not proved, and differences can be found by gender, age, and socio-economic status of participants.
The fourth review focuses on physical exercises and activities in the schools [17]. Health authorities are concerned about the increased sedentariness of children and adolescents, because of the risks sedentariness entails - obesity, cardiovascular and cerebrovascular diseases and their consequences. Over $30 \%$ of those aged 15 and over, in 23 out of 36 European Countries, are not making enough exercise [35]. According to the WHO latest report [36], obesity and overweight affect children and adolescents with a prevalence as high as $27 \%$ among 13-year-olds, and 33\% among 11 year-olds in some European countries, such as Greece, Portugal, Ireland, Spain and the UK.

Schools are an ideal setting to promote and enhance physical activity, because not only school gyms, but also schoolyards and even classrooms could be used as suitable places to exercise. Nevertheless, the optimal dose of moderate to vigorous physical activity individuated by guidelines to ensure children's healthy growth and to avoid the risk of metabolic and cardiovascular diseases is higher - 60 minutes/day.

Forty-seven papers regarding preventive/intervention programs carried out throughout Europe were included in the review. The great number of studies identified by the research testifies researchers' interest in this field. However, the findings of school-based physical activity interventions were not always positive; major differences emerged between interventions that promoted or encouraged physical activity, and those that were effectively based on physical activity.

The fifth review focuses on school-based alcohol and other drug prevention programs [18]. The use of alcohol and other drugs by young people is a serious public health concern and could lead to adverse medical, psychological and social consequences, even in the long term. Recent studies outside Europe show that approximately one-quarter of teenagers (aged 14-19 years) have tried an illicit drug, two-thirds (65\%) have consumed a full serve of alcohol in the past year and almost one-fifth (20\%) have consumed alcohol at levels that put them at risk of injury at least once in the past month (defined as more than four drinks on a single occasion) [37]. The recent European School Survey Project on Alcohol and Other Drugs (ESPAD), in a sample of more than 100,000 students from 35 European countries, found that about $90 \%$ of 15-16 year-old students have drunk alcohol at least once in their life, with $50 \%$ of these having become intoxicated at least once [38].

Early initiation to drug use (i.e. before the age of 18) is a risk factor for developing substance use disorders and comorbid mental health problems in adulthood [39, 40].

Schools may be the ideal location for promoting health and delivering healthcare services related to substance use, especially when adopting brief intervention programs. In recent years, several school-based prevention programs have been developed against the use of alcohol and other drugs, including motivational, educational, social, and CBT treatment programs. However, it is not clear whether these programs are really effective in terms of outcome and cost.

The review included thirty studies involving 70165 participants. The included studies were mostly based on social 
$(n=7)$, educational $(n=7)$, motivational $(n=4)$, Cognitive Behavioral Therapy $(\mathrm{n}=3)$ and behavior imaging models $(\mathrm{n}=3)$ interventions. The results seem encouraging, despite severe methodological inconsistency in many of these studies.

As a matter of fact, shortcomings and methodological limitations affect most RCTs targeting the school as a setting of intervention.

There was a general lack of standardized measures in the evaluation of the outcomes and of the mediators and moderators. Sample sizes were often too small to apply multivariate analyses. In many cases, follow-up was too short to establish stability of the effects, or there was no follow-up at all. More importantly, only a minority of the trials were based on an apriori model.

\section{CONCLUSION}

The included reviews are a first contribution to address future European research and interventions, in particular concerning the multiple ways through which European policies could support the schooling and wellbeing of children and adolescents.

The school is the core setting for children and adolescents to attain mental health and well-being, in terms of reaching the target (i.e. children and adolescents, but also their families and the local community at large), as well as in terms of promoting interaction with other sectors (healthcare, social services, leisure activities and so on).

However, it must be taken into consideration that schools in Europe are often underfinanced while being overburdened with duties and expectation from the society at large. Therefore, the action for mental health and well-being in schools must be defined in agreement with the schools themselves, according to their planning procedure and timetable, and diluting the action along the school curricula.

The mental health and well-being of children and adolescents holds an important and steadfast place on the political agenda of European National governments. While the level of attention devoted to the issue is common across Europe, the strategies adopted vary not only among States but also within States, particularly at the regional level. This calls for common and agreed policy recommendations as the basis for a European action framework.

\section{CONFLICT OF INTEREST}

The authors confirm that this article content has no conflict of interest.

\section{ACKNOWLEDGEMENTS}

Declared none.

\section{REFERENCES}

[1] Kessler RC, Berglund P, Demler O, Jin R, Merikangas KR, Walters EE. Lifetime prevalence and age-of-onset distributions of DSM-IV disorders in the national comorbidity survey replication. Arch Gen Psychiatry 2005; 62: 593-602.

[2] Kessler RC, Amminger GP, Aguilar-Gaxiola S, Alonso J, Lee S, Ustün TB. Age of onset of mental disorders: A review of recent literature. Curr Opin Psychiatry 2007; 20: 359-64.
[3] Wittchen HU, Jacobi F, Rehm J, et al. The size and burden of mental disorders and other disorders of the brain in Europe 2010. Eur Neuropsychopharmacol 2011; 21: 655-79.

[4] Carta MG, Kovess V, Hardoy MC, et al. Psychosocial wellbeing and psychiatric care in the European communities: Analysis of macro indicators. Soc Psychiatr Psychiatric Epidemiol 2004; 39(11): 883-92.

[5] WHO - World Health Organization. The World Health Report 2008: Primary Healthcare, Now More Than Ever. Geneva: WHO 2008.

[6] OECD - Organisation for Economic Co-operation and Development. Health Reform: Meeting the Challenge of Ageing and Multiple Morbidities. OECD Publishing 2011. http://dx.doi.org/10.1787/ 9789264122314-en

[7] Campion J, Bhui K, Bhugra D. European Psychiatric Association. European Psychiatric Association (EPA) guidance on prevention of mental disorders. Eur Psychiatry 2012; 27: 68-80.

[8] European Pact for Mental Health and Well-being. Brussels: European Commission 2008. (http://ec.europa.eu/health/ph_determinants/ life_style/mental/docs/pact_en.pdf. [Accessed 22 August 2014].

[9] EU Joint Action on Mental Health and Well-being. European Commission 2013. http://www.mentalhealthandwellbeing.eu/

[10] Joint Action on Mental Health and Wellbeing WP7 on Mental Health and Schools. Regione Veneto 2014. http://www.regione.veneto.it/web/sanita/joint-action

[11] Currie C, Zanotti C, Morgan A, et al., Eds. Social determinants of health and well-being among young people. Health Behaviour in School-aged Children (HBSC) study: International report from the 2009/2010 survey. Copenhagen: WHO Regional Office for Europe 2012. (Health Policy for Children and Adolescents, No. 6).

[12] WHO - World Health Organization. Summary report: Prevention of mental disorders - effective interventions and policy options. Geneva: WHO 2004.

[13] Olesen J, Gustavsson A, Svensson M, Wittchen HU, Jönsson B. CDBE2010 study group. European Brain Council. The economic cost of brain disorders in Europe. Eur J Neurol 2012; 19: 155-62.

[14] Sancassiani F, Pintus E, Holte A, et al. Enhancing youths' emotional and social skills to promote their wellbeing and positive development: a systematic review of universal school-based randomized controlled trials. Clin Pract Epidemiol Ment Health 2015; 11: 21-40.

[15] Cossu G, Cantone E, Pintus M, et al. Integrating children with psychiatric problems in the classroom. A systematic review. Clin Pract Epidemiol Ment Health 2015; 11: 41-57.

[16] Cantone E, Piras AP, Vellante M, et al. Interventions on bullying and cyberbullying in schools: A systematic review. Clin Pract Epidemiol Ment Health 2015; 11: 58-76.

[17] Mura G, Rocha NBF, Helmich I, et al. Physical activity interventions in schools for improving lifestyle in European Countries. Clin Pract Epidemiol Ment Health 2015; 11: 77-101.

[18] Agabio R, Trincas G, Floris F, Mura G, Sancassini F, Angermeyer MC. A systematic review of school-based alcohol and other drug prevention programs. Physical activity interventions in schools for improving lifestyle in European Countries. Clin Pract Epidemiol Ment Health 2015; 11: 102-112.

[19] Kovess V, Carta MG, Pez O, et al. The School Children Mental Health in Europe (SCMHE) project: Design and first results. Clin Pract Epidemiol Ment Health 2015; 11: 113-123.

[20] Weare K, Nind M. Mental health promotion and problem prevention in schools: What does the evidence say? Health Promot Int 2011; 26 (Suppl 1): i29-i69.

[21] Catalano RF, Berglund ML, Ryan JAM, Lonczak HS, Hawkins JD. Positive youth development in the United States: Research findings on evaluations of positive youth development programs. Ann Am Acad Pol Soc Sci 2004; 591: 98-124.

[22] Durlak JA, Weissberg RP, Dymnicki AB, Taylor RD, Schellinger $\mathrm{KB}$. The impact of enhancing students' social and emotional learning: A meta-analysis of school-based universal interventions. Child Dev 2011: 82: 405-32.

[23] Stewart-Brown S. What is the evidence on school health promotion in improving health or preventing disease and specifically, what is the effectiveness of the health promoting schools approach? Copenhagen: WHO Regional Office for Europe 2006. (Health Evidence Network report; http://www.euro.who.int/_data/assets/ pdf_file/0007/74653/E88185.pdf) [Accessed 22 August 2014]. 
[24] Durlak JA, Wells AM. Primary prevention mental health programs for children and adolescents: A meta-analytic review. Am J Community Psychol 1997; 25: 115-52.

[25] Tobler NS, Roona MR, Ochshorn P, Marshall DG, Streke AV, Stackpole KM. School-based adolescent drug prevention programs: 1998 meta-analysis. J Prim Prev 2000; 30: 275-336.

[26] Bond LA, Hauf AMC. Taking stock and putting stock in primary prevention: charachteristics of effective programs. J Prim Prev 2004; 24: 199-221.

[27] Dusenbury L, Falco M. Eleven components of effective drug abuse prevention curricula. J Sch Health 1995; 65; 420-5.

[28] Gresham FM. Best practices in social skills training. In: Thomas A, Grimes J, Eds. Best practices in school psychology-III). Washington, DC: National Association of School Psychologists 1995: pp. 1021-30.

[29] Schachter HM, Girardi A, Ly M, et al. Effects of school-based interventions on mental health stigmatization: A systematic review. Child Adolesc Psychiatry Ment Health 2008; 2: 18.

[30] Angermeyer MC, Matschinger $\mathrm{H}$. Social distance towards the mentally ill: Results of representative surveys in the federal republic of Germany. Psychol Med 1997; 27: 131-41.

[31] Olweus, D. Bullying at School: What We Know and What We Can Do. Cambridge, Mass: Blackwell Publishers Ltd 1993.

[32] Card NA, Hodges EV. Parent-child relationships and enmity with peers: the role of avoidant and preoccupied attachment. New Dir Child Adolesc Dev 2003; 102: 23-37.
[33] Olweus D. Bullying at school: Basic facts and an effective intervention programme. Promot Educ 1994; 1: 27-31.

[34] Merrell KW, Gueldner BA, Ross SW, Isava DM. How effective are school bullying intervention programs? A meta - analysis of intervention research. Sch Psychol Quart 2008; 23: 26-42.

[35] OECD - Organisation for Economic Co-operation and Development. Health at a Glance: Europe 2012, OECD Publishing 2012. http://dx.doi.org/10.1787/9789264183896-en

[36] Global Status Report on Non-Communicable Diseases. WHO 2010. http://www.who.int/nmh/publications/ncd_report2010/en/

[37] AIHW - Australian Institute of Health and Welfare. 2010 National Drug Strategy Household Survey report. Drug statistics series no. 25. Cat. no. PHE 145. Canberra: AIHW 2011. http://www.aihw.gov.au/publication-detail/?id=32212254712. [Accessed 22 August 2014]

[38] Hibell B, Guttormsson U, Ahlström S, et al. The 2011 ESPAD report - substance use among students in 36 European countries, 2011, http://www.espad.org/en/References--Literature/The-2011ESPAD-Report---Substa/

[39] Behrendt S, Beesdo-Baum K, Zimmermann P, et al. The role of mental disorders for the risk and speed of transition to alcohol use disorders among community youth. Psychol Med 2011; 41: 107385.

[40] Chen CY, Storr CL, Anthony JC. Early-onset drug use and risk for drug dependence problems. Addict Behav 2009; 34: 319-22.

Received: September 15, 2014

Revised: October 01, 2014

Accepted: October 05, 2014

(C) Carta et al.; Licensee Bentham Open.

This is an open access article licensed under the terms of the Creative Commons Attribution Non-Commercial License (http://creativecommons.org/licenses/by-nc/3.0/) which permits unrestricted, non-commercial use, distribution and reproduction in any medium, provided the work is properly cited. 